\title{
A Contrastive Analysis of First and Second Language Learning
}

\author{
Rui Ting Wu \\ Faculty of Education, University of Tasmania, Launceston, TAS, Australia \\ Van Tai Le \\ The Tasmanian School of Business and Economics, University of Tasmania, Hobart, TAS, Australia
}

Jin Jin Lu

Faculty of Education, University of Tasmania, Launceston, TAS, Australia

\begin{abstract}
Second language learning is increasingly important in the modern world. Second language learners often wonder why they have experienced so many difficulties when learning a second language, while they did not experience it when learning a first language. This study aimed to discover a way in which the second language learning can benefit from the first language learning. A random sample of 50 second language learners was used. The data gathering consisted of a questionnaire. A combination of both quantitative and qualitative approaches was utilised to analyse the data. The findings confirmed that the first language is indeed learned more easily than the second language. A number of recommendations have been made in relation to this study to assist second language learners to improve their second language learning.
\end{abstract}

Index Terms - language learning, first and second language, input, output

\section{INTRODUCTION}

It is well known that almost all human beings know a language, except those with severely damaged brains or severely interrupted socialisation (i.e., "wolf children"). According to Vygotsky (1978, p. 89), "language arises initially as a means of communication between the child and the people in his/her environment". In order to live in the world, people need to communicate via a language. At least, they need to know one language, that is, a first language (L1). However, with the growing internationalisation in politics and economy of the modern society, citizens with more than one language are increasingly needed. According to Lessow-Hurley's statement (1990, p. 128), "it is common wisdom that you can buy in any language, but you should sell in the language of your customer. Around the world, sales people are expected to be multilingual". As a result, people need to learn another one or two languages, namely, second language (L2). Second language learning, according to Spolsky (1999, p. 181), "is the process by which an individual who has, during the first few years of life, acquired one language (or, often, more than one language) from his or her caretakers or peers goes on to add one or more new languages to his or her repertoire".

\section{THE RESEARCH Aim AND THE QUESTIONS}

In this study, the purpose of contrastively analyzing first and second language learning is to find a way in which the second language learning can benefit from the first language learning. This study pursued the following four questions in order to achieve this main aim:

1. What are L2 learners' views on the difficulty of L1 learning?

2. What are L2 learners' views on the difficulty of L2 learning?

3. What are L2 learners' views on reasons of that the first language is learned more easily than the second language?

4. What are L2 learners' views on how to improve their second language learning?

The findings from this study have the potential to assist L2 learners to improve their second language learning.

\section{THE SignificANCE OF THE RESEARCH}

It is widely recognized that children learn their native/first language naturally and successfully. Whatever their culture, all normal children acquire their native language at a given time of life and in an appropriate linguistic environment that provides sufficient language input and output. Children have no difficulty at all when learning their first language. However, millions of second language learners are often at pains to point out that second language learning poses difficulties which they did not face when learning their mother tongue. They are puzzled about why they cannot understand or use a second language as fluently and correctly as they do with their first language, even though they have been striving to learn it for many years. Second language learners often complain that the first language is 
learned more easily than the second language when they are struggling to adjust to a new phonological system and culture. As Mackey (as cited in Ellis, 1990, p. 22) put it, "the learning of one language in childhood is an inevitable process; the learning of a second language is a special accomplishment". People often wonder whether L2 learners could duplicate the way of first language learning. The contrastive analysis of first and second language learning thus become of great importance for second language teachers and learners for two main purposes. According to Ellis (1990, p. 22),

the first was to emphasize the relative ease of L1 learning and to make out a case for commencing foreign language instruction as early as possible in order to tap the natural language learning capacity of the young child. The second purpose was to dispute the view that the classroom should try to imitate 'real life'. L1 learning took place successfully in 'real life', but FL learning required setting up the 'optimal conditions' for learning in order to overcome the various problems.

The study is significant for L2 learners. This study seeks to examine why the first language is learned more easily than the second language, and how L2 learners have to improve their second language learning. An awareness of these learning approaches will help both struggling and advanced L2 learners with their language learning.

\section{LITERATURE REVIEW}

According to $\mathrm{Wu}$ (2013, p. 1), "English has become an important international language due to the effects of rapid globalization". Richards and Rodgers (1986, p. 1) also pointed out, "English has become the world's most widely studied foreign language". In fact, "over one half of the one billion English speakers of the world learn English as a second or foreign language" (Brown, 1994, p. 122). However, these L2 learners have experienced many difficulties and problems when learning a different phonological system. These difficulties were particularly serious when non-English native speakers pursuing a higher education in a native English speaking country. A number of studies have attempted to identify the difficulties and problems related to culture, academic learning, psychology experienced by non-English speaking international students (NESI) in a native English learning environment (Spencer-Oatey and Xiong, 2006). Levy, Osborn, and Plunkett (2003) found that a significant number of international students demonstrated poor performance levels and even subject failures in their first semester or year of study. This point of view was supported by Makepeace (1989) who indicated that the failure rate for international students attending courses in the United Kingdom was higher than that of local students.

Many researchers believed that these failures resulted from their English deficiencies. Ying (2003) pointed out that English writing skills were particularly necessary for successful completion of written assignments, and essential for academic achievement. This perception was supported by the view of that competence in English was a predictor of academic success and greater satisfaction with an overseas tertiary experience (Barker, Child, Gallios, Jones, \& Callen, 1991; Church, 1982; Wintergerst, DeCapua, \& Verna, 2003; Ying \& Liese, 1991). Many studies have also revealed that some NESI students believed that their lack of English competence had hindered their full participation in tutorials, classroom discussions, and interactions with academic staff at university (Barker, Child, Gallois, Jones, \& Callan, 1991; Robertson, Line, Jones, \& Thomas, 2000). As Felix and Lawson (1994, p. 67) stated, "poor English and poor argument or analysis [are] inextricably linked". As a result, many researchers examined learning strategies to improve the second language learning (Macaro, 2001; Oxford, 2003; Wenden \& Rubin, 1987). However, very few studies examined the difference between first and second language learning and how the second language learning can benefit from the first language learning. Therefore, this study will examine reasons of that the first language is learned more easily than the second language, and how L2 learners have to improve their second language learning.

\section{Methodology}

This study utilised both quantitative and qualitative methods in order to gain the strengths of both methodological methods and to potentially offset their respective weaknesses. This study was based on a survey design which, according to Creswell (2003, p. 153), "provides a quantitative or numeric description of trends, attitudes, or opinions of a population by studying a sample of that population". From the results the researcher can make generalisations about the population being studied. The data gathering consisted of a questionnaire (see Appendix). The first three research questions were examined through the closed questions of the questionnaire, which was the first step in the data collection. The open-ended questions further explored the first three research questions and also investigated the fourth research question.

This study recruited fifty (50) English as a second language learners who were studying or living in Australia. A pilot study of questionnaire was conducted prior to the study commencing in order to assess the feasibility of the later fullscale study and to identify any logistical problems. Burns (2000) noted that a pilot study was an opportunity to enhance the validity and reliability of the research. It also enabled the researcher to confirm the appropriate research structure and design of the study. Ten (10) L2 learners participated in this pilot study. After a slight change on the questionnaire according to the feedback from the pilot study, hard copies of questionnaires and details of the study were posted to potential participants. 
The data analysis in this study employed both quantitative and qualitative methodological methods. The closed questions of the questionnaire were divided into two parts. The first section (Part A) sought information regarding the first language of the respondents in addition to their gender, age, length of learning English as a second language, and highest qualification completed. The second section (Part B) consisted of 27 questions related to the first three research questions. The analysis of the questionnaires was aided by the Statistical Package for Social Sciences (SPSS) and focused on answering the research questions.

\section{FINDINGS}

In this research study, all of the 50 questionnaires distributed were completed and returned by the participants. All of the 27 closed questions were answered, whilst the four open-ended questions received 30 responses for each question.

It was commonly acknowledged by the participants that L1 was learned more easily than L2. The difficulty of L1 learning in listening and speaking was not noticed by all of the participants, whilst all of them agreed to have experienced different difficulties when learning a second language. The reasons for the difficulties were summarized into two categories, i.e., extrinsic and intrinsic psychological reasons. The extrinsic reasons included:

1. The first language learning environment is richer in interaction and more supportive than that of the second language.

2. Children spend much more time in learning the first language than L2 learners spend in learning the second language.

3. The first language is usually learned by constant interaction, in a natural fashion, while second language is normally learned by formal instruction which mainly uses the grammar-translation approach.

The intrinsic psychological reasons included the attitude towards making mistakes and the attitude towards being considered a show-off.

According to the data from questionnaires, gender difference and cultural difference were not found in the views on the difficulty of L1 and L2 learning. Many suggestions were made for L2 learners to improve their second language learning.

\section{DISCUSSION}

This section will analyse the findings in relation to the research questions guiding this study. The data analysis will also involve discussion of issues generated from the data and whether these are validated or refuted in existing literature related to this topic. When citing a participant, the participant will be coded as "QP A", "QP B, " or "QP C", and so on.

A. What Are L2 Learners' Views on the Difficulty of L1 Learning?

According to the responses from 50 questionnaires, all participants (100\%) revealed that they did not feel any difficulty in L1 learning. As the participants stated:

I do not think that I have ever experienced any difficulty when learning a first language. It was just acquired spontaneously (QP A).

Well, I have never realized the difficulty of learning a first language. I feel like that my first language was learned automatically when we grew up. When we were infants, we listened to our parents and people around our families and then acquired the first language. Gradually, we talked and communicated with other people (QP B).

Only a few participants $(10 \%)$ indicated that they had a little trouble when learning reading of their first language. According to a participant's statement:

I have to work hard and practise because the vowels and consonants in my first language are difficult to identify (QP C).

$20 \%$ of participants agreed that they had problems when learning the writing of their first language. As a participant stated:

Grammar and spelling of my first language are hard. I have to really work hard to learn them (QP D).

B. What are L2 learners' views on the difficulty of L2 learning?

Nearly all participants $(98 \%)$ revealed that they found difficulty in L2 learning. As they stated:

I have found a lot of problems when learning a second language because the language system is very different from my first language $(Q P E)$.

I understood nothing when I first came to Australia. But I did not have problem when I went shopping in supermarkets because the price was written there, all what I needed was to pay (QP F).

I could not communicated with English native speakers because I did not understand them, and when I talked, they did not understand me ( $Q P G)$.

I have found it hard to read English fast and hard to comprehend the text. Writing assignments in English is more difficult. I do not remember the words. Whenever I wrote something, I had to look up the dictionary. The writing speed is very $\operatorname{slow}(Q P H)$.

C. What are L2 learners'views on reasons of that the first language is learned more easily than the second language? 
According to Bock-Mi Lee's statement (1996, p. 96), "the first language is normally learned as a child during the optimal or critical age, since the child can figure out the language by hearing and using it. On the other hand, the second language is normally learned later by formal teaching or schooling". Even though the critical period does play an important role in language learning, the discussion on the difference of first and second language learning during the critical period is not relevant to improve the second language learning since most of L2 learners have already missed most of the period. Therefore, other reasons, which were acknowledged by the participants to explain why the first language is learned more easily than the second language, are important for L2 learners to know. They can be summarized into two categories, i.e., extrinsic and intrinsic psychological reasons.

1) Extrinsic reasons

All participants $(100 \%)$ agreed that the first language learning environment is richer in interaction than that of the second language and learners produce first language more than second language. As the participants complained:

Children obtain more input when learning a first language than L2 learners do when learning a second language. Assuming children sleep for 14 hours a day, they may be exposed to the first language for up to 10 hours a day, compared with second language learners being exposed to the target language only a few hours weekly, from school teachers $(Q P I)$.

When children learn their first language, the communication is required more than when L2 learners learn the second language. Almost all daily interaction from parents, teachers, peers, and siblings around children is in first language. This requires that they have to respond others in their first language to express their needs, ideas and emotions, and thus they have many opportunities to engage in one to one interaction with a wide range of people and for a wide range of purposes (QP J).

Children have no choice of other languages when they learn their first language. So children are able to concentrate on one language and have to try their best to learn to speak it for their daily communicative needs $(Q P K)$.

However, "it is impossible to conceive second language acquisition without input in some form or other" (Alcon, 1998, p. 343). It is hard for L2 learners to be exposed to the second language as much as the first language unless they go to the country where the target language is spoken as the first language. According to Yule (1996, p. 175), "language a child learns is not genetically inherited, but is acquired in a particular language-using environment". In order for successful language acquisition to take place, learners have to produce the language in the context of conversation. Brown (2000, p. 5) also pointed out, "output is achieved by using this language for communication". When children frequently repeat experiences of combining linguistic and nonlinguistic strategies, they gradually master the linguistic system and its meanings. Children have to communicate in only one language, and thus they can produce first language more than L2 learners speak second language because L2 learners have the first language as another choice for communication. According to Rosansky (as cited in Birdsong, 1999, p. 5), "when faced with a problem, [children] can focus (and then only fleetingly) on one dimension at a time, this lack of flexibility and lack of decentration may well be a necessity for language acquisition". Vertriglia (1982, p. ix) also noted, "the more language is shared, the better it is learned".

A large majority of participants (94\%) agreed that the first language learning environment is more supportive than that of the second language. As they stated:

When children learn their first language, they are usually egocentric at this time. So the environment when learning the first language has more advantages over when learning the second language (QP L).

This view was supported by Rosansky (as cited in Birdsong, 1999, p. 5) who pointed out, "initial language acquisition takes place when the child is highly centered [i.e. in stages prior to Formal Operations]". Campbell and Green (2000, p. 81) also noted, "language development relies upon the active and supportive assistance of adults in all of the social contexts that represent the culture in which the child is growing". Almost all adults around the children patiently repeat or paraphrase when children do not understand the meaning, and give the children a model to copy to learn the appropriate expression when they say something that is not the same as the accepted use. Parents are also often surprised by their children's everyday language improvement. They praise and encourage their children's learning all the time. This definitely gives children much confidence, and then children may feel free to take risks and make mistakes in learning the first language.

However, L2 learners do not have the same supportive language learning environment as children have when learning their first language. L2 learners mainly learn the second language by formal instruction in school settings and the school teachers usually correct their mistakes rather than praising their improvement. This may discourage their learning in the long run. As Yule (1996, p. 195) noted, "a language-learning situation that encourages success and accomplishment must consequently be more helpful than one that dwells on errors and corrections". Indeed, the learner who tries to learn and communicate in second language with courage will tend to be more successful.

All participants $(100 \%)$ agreed that children spend much more time in learning the first language than L2 learners spend in learning the second language, and L2 learners normally lack daily communication needs to learn their second language. As the participants complained:

Between the ages of 1 and 6 years, children learn their first language with little else to do. Except for sleeping approximately 14 hours a day, children may learn their first language for up to 10 hours a day from television, radio or 
communicating with parents, caretakers, peers or siblings. By 6 years of age, they would have already learned their first language for more than 18,000 hours (QP M).

L2 learners such as students in Chinese primary and secondary school study English as a second language only one or two hours a day. Even though we learn English for 10 years, the total amount of time will be at most 730 hours which is not enough to produce very advanced English speakers (QP N).

Most people attempt to learn another language during their teenage or adult years. Adults, especially those married and with children, have a lot of other responsibilities. Work occupies almost all adults' time (QP O).

According to Bourgeois (1999, p. 90), "about half of students questioned stated that the major difficulty was the lack of time because of familial obligations". Research (Bourgeois, 1999) also showed that the most common obstacles to adults' learning are the costs incurred and lack of time.

$90 \%$ of participants agreed that the first language is usually learned by constant interaction, in a natural fashion, while second language is normally learned by formal instruction which mainly uses the grammar-translation approach. This approach gives little help to learners' communicative skills. As Krashen and Terrell (1988, p. 55) noted, "language is best taught when it is being used to transmit a message not when it is explicitly taught for conscious learning".

2) Intrinsic reasons

All participants $(100 \%)$ responded agree or strongly agree on the view of that L2 learners often find it very stressful when they are unable to express themselves clearly and correctly in the second language. $78 \%$ of participants indicated that L2 learners usually worry that they may be considered to be "showing-off" when they talk in a second language in public. This view reflected a similar opinion to Richard-Amato (1996, p. 25) who said that adults' strong selfconsciousness leads to L2 learners' increased inhibitions and anxiety with age and they may find themselves afraid to make errors. Birkhill \& Schaie (1975) also noted that L2 learners are usually more cautious than young L1 learners and unlikely to venture a response if they are unsure of its correctness. A questionnaire of 300 adult English learners carried out by Wu Huifang (2002, p. 61) showed that about $80 \%$ of Chinese adults feel embarrassed or ashamed of making mistakes. Children, however, do not have to worry about making mistakes, because their learning first language 'risktake' is almost in a stress-free environment. Their very small language improvement would even surprise and excite their parents. They are praised and encouraged during almost all the first language learning process, which definitely free their nervousness in language learning.

\section{What Are L2 Learners' Views on How to Improve Their Second Language Learning?}

According to the responses to the open-ended questionnaires, many strategies were frequently mentioned (between 3 -5 times) to improve their second language learning. As they responded:

What I did is to turn on the tape-recorder or English TV programs every day when I am at home. Even though I am doing something else, such as cooking or eating rather than reading or writing English, I can still study English by listening to it. When I am on the way to and from school, I can also listen to English on a pocket-sized tape-recorder or a MP3 player. In this way, I have got an increased exposure to English (QP P).

I try to communicate with other students in English outside the class or school. At first we found it too hard to communicate, but once we overcame the problem and got used to communicating in English, our speaking English were performed without hesitation or reflection $(Q P Q)$.

I make good use of short times, like 5 or 10 minutes, when waiting for buses or whatever else, because short times can accumulate. I also try my best to recall what I have learned before sleeping. I have found that the effect of memorization recall during this period of time is much better than that of recall during the day time $(Q P R)$.

These views were supported by Spolsky (as cited in O’Malley and Chamot, 1990, p. 12) who noted, "necessary conditions in second language acquisition are target language input, motivation, and practice opportunities".

Using first language for translation as an important learning approach was mentioned twice. The use of first language knowledge can facilitate the progress of L2 learners towards the target language. As Gibbons (1991, p 62) noted, "ignoring children's first languages is wasteful because it ignores one of the greatest resources they bring to school". Ringbom (1986, p. 150) also pointed out, "especially for the beginner, one obvious way of facilitating the foreign language learning process is to rely upon his/her first language or other languages he/she may know". The results of a survey into student attitudes towards this idea showed that the beginning and intermediate L2 learners generally agreed with the teacher using the first language in the classroom more than the advanced L2 learners. The survey reported that $66 \%$ of beginning L2 learners and 58\% of intermediate L2 learners preferred the teacher to use the first language in teaching, compared with $29 \%$ of advanced L2 learners (Prodromou, 2006).

Having a positive psychological attitude towards making mistakes was also mentioned twice. This view reflected a similar opinion to Gibbons (1991, p. 11) who said that L2 learners' attitudes to learning and their confidence are "key psychological factors in successful second language learning".

\section{RECOMMENDATIONS}

Based on the responses by L2 learners, recommendations are made to improve L2 learning. They were listed as follows:

1. L2 learners should increase the amount of input and output of a second language as much as possible. 
2. L2 learners can lengthen their time in learning the second language by making use of short times and the retention work before sleeping.

3. Making good use of first language to aid second language learning is an important learning approach.

4. Developing a positive psychological attitude towards making mistakes and "showing-off" would be more successful in second language learning.

\section{CONCLUSION}

This study examined L2 learners' views on the difficulty of L1 and L2 learning, and reasons of that the first language is learned more easily than the second language. The findings confirmed that the first language is learned more easily than the second language. However, it is nearly impossible for L2 learners to duplicate children's interactive approaches in a natural fashion when learning the second language. A number of recommendations have been made in relation to this study to assist second language learners to improve their second language learning. This research could be further developed if the research to be undertaken in order to reveal the specific procedure of how to make the best use of the advantages of first language learning to serve their second language learning.

\section{APPENDIX}

\section{Questionnaire to examine first and second language learning}

1) Part A: Please highlight only one choice.
1. Your native language: a. Chinese
b. Korean
c. Vietnamese
d. Other (please specify)

2. Gender: a. Male

b. Female
3. Age:
a. $17-24$
b. $25-35$
c. $36-50$
d. Over 50

4. Length of learning English as a second language (up to now):
a. Less than 12 months
b. Over one year to four years
c. Over four years to nine years
d. Over nine years

\section{Highest qualification completed}

a. High school b. Certificate/Diploma c. Bachelor degree d. Masters degree e. Doctoral degree f. Other(s) (please specify)

2) Part B: Please highlight your most appropriate response.

a) Directions: Please indicate your most appropriate response by using the following criteria:
SDA= Strongly Disagree;
DA= Disagree;
NS=Not Sure;
A= Agree;
SA = Strongly Agree

\begin{tabular}{|c|c|c|}
\hline No. & A contrastive analysis of first and second language & Weighted Scores \\
\hline & - Your views on the difficulty of L1 learning & \\
\hline 6 & I did not feel any difficulty in L1 learning. & SDA $\quad$ DA $\quad$ NS A $\quad$ SA \\
\hline 7 & I think it is difficult to learn a first language. & SDA DA NS A SA \\
\hline 9 & I encountered many problems when learning the speaking of my first language. & SDA $\mathrm{DA}$ NS A $\mathrm{SA}$ \\
\hline 10 & I encountered many problems when learning the reading of my first language. & SDA DA NS A SA \\
\hline 11 & I encountered many problems when learning the writing of my first language. & SDA $\quad$ DA $\quad$ NS A SA \\
\hline 12 & I did not feel any difficulty in L2 learning. & SDA DA $\quad$ NS A SA \\
\hline 13 & I have experienced many difficulties when learning a second language. & SDA $\quad$ DA $\quad$ NS A $\quad$ SA \\
\hline 14 & I have found difficulties in understanding English native speakers' accent. & SDA DA NS A SA \\
\hline 15 & I have found difficulties in communicating with English native speakers. & SDA DA NS A SA \\
\hline 16 & I have found difficulties in reading in English. & SDA $\mathrm{DA}$ NS A SA \\
\hline 17 & I have found difficulties in writing assignments in English. & SDA $\mathrm{DA}$ NS A $\mathrm{SA}$ \\
\hline 19 & The first language learning environment is richer in interaction. & SDA DA NS A SA \\
\hline 20 & Learners produce first language more than second language. & SDA DA NS A SA \\
\hline 21 & $\begin{array}{l}\text { The first language learning environment is more supportive than that of the } \\
\text { second language. }\end{array}$ & SDA DA NS A SA \\
\hline 22 & The length of learning a first language is longer than learning a second language. & SDA DA NS A SA \\
\hline 23 & $\begin{array}{l}\text { Children spend much more time in learning the first language than L2 learners } \\
\text { spend in learning the second language. }\end{array}$ & SDA DA NS A $\quad$ SA \\
\hline 24 & $\begin{array}{l}\text { L2 learners normally lack daily communication needs to learn their second } \\
\text { language. }\end{array}$ & $\begin{array}{lllll}\text { SDA } & \text { DA } & \text { NS } & \text { A } & \text { SA }\end{array}$ \\
\hline 25 & $\begin{array}{l}\text { The first language is usually learned by constant interaction, in a natural fashion, } \\
\text { while second language is normally learned by formal instruction which mainly } \\
\text { uses the grammar-translation approach. }\end{array}$ & $\begin{array}{lllll}\text { SDA } & \text { DA } & \text { NS } & \text { A } & \text { SA }\end{array}$ \\
\hline
\end{tabular}




\begin{tabular}{|l|l|cc|}
\hline $\mathbf{2 6}$ & $\begin{array}{l}\text { L2 learners often find it very stressful when they are unable to express } \\
\text { themselves clearly and correctly in the second language. }\end{array}$ & SDA DA NS A SA & DA learners usually worry that they may be considered to be "showing-off" when \\
they talk in a second language in public. & SDA DA NS A SA & 27
\end{tabular}

\section{Open-ended questions:}

1. Please write down any comments you would like to make regarding the difficulty of L1 learning.

2. Please write down any comments you would like to make regarding the difficulty of L2 learning.

3. Please write down any comments you would like to make regarding reasons of that the first language is learned more easily than the second language.

4. Please write down any comments you would like to make regarding how to improve their second language learning

\section{REFERENCES}

[1] Alcon, E. (1998). Input and input processing in second language acquisition. IRAL, International Review of Applied Linguistics in Language Teaching. Heidelberg, 36(4), 343-362.

[2] Barker, M., Child, C., Gallios, C., Jones, E., \& Callen, V. (1991). Difficulties of overseas students in social and academic situations. Australian Journal of Psychology, 43, 79-84.

[3] Birdsong, D. (1999). Second Language Acquisition and the Critical Period Hypothesis. Mahwah, N.J.: Erlbaum.

[4] Birkhill, W. R., \& Schaie, K. W. (1975). The effect of differential reinforcement of cautiousness in the intellectual performance of the elderly. Journal of Gerontology, 30, 578-583.

[5] Bourgeois, E. (1999). The Adult University. Buckingham: Society for Research into Higher Education \& Open University Press.

[6] Brown, H. D. (2000). Principles of Language Learning and Teaching. Englewood Cliffs, New Jersey: Prentice Hall Regents.

[7] Brown, H. D. (1994). Teaching by Principles: An Interactive Approach to Language Pedagogy. Upper Saddle River, N.J.: Prentice Hall Regents.

[8] Burns, R. B. (2000). Introduction to Research Methods ( $4^{\text {th }}$ ed.). Frenchs Forest: Pearson Education.

[9] Campbell, R., \& Green, D. (2000). Literacies and Learners: Current Perspectives. [Frenchs Forest, N.S.W.]: Prentice Hall Australia.

[10] Church, A. (1982). Sojourner adjustment. Psychological Bulletin, 91, 540-572.

[11] Creswell, J. W. (2003). Research Design: Qualitative, Quantitative, and Mixed Methods Approaches (2 ${ }^{\text {nd }}$ ed.). Thousand Oaks, Calif.; London: Sage.

[12] Ellis, R. (1990). Understanding Second Language Acquisition. Oxford: University Press.

[13] Ellis, R. (1985). Understanding Second Language Acquisition. Oxford [Oxfordshire]: Oxford University Press.

[14] Felix, U., \& Lawson, M. (1994). Evaluation of an integrated bridging program course on academic writing for overseas postgraduate students. Higher Education Research and Development, 13(1), 59-70.

[15] Fishman, J. A (1999). Handbook of Language \& Ethnic Identity. Oxford: Oxford University Press.

[16] Gibbons, P. (1991). Learning to Learn in a Second Language. Newtown, N.S.W: Primary English Teaching Association.

[17] Kellerman, E., \& Smith, M. S. (Eds.). (1986). Crosslinguistic Influence in Second Language Acquisition. New York: Pergamon Institute of English.

[18] Krashen, S. D., \& Terrell, T. D. (1988). The Natural Approach: Language Acquisition in the Classroom. London: Prentice Hall Europe. Retrieved October $10^{\text {th }}, 2006$ from http://www.osea-cite.org/class/SELT_materials/SELT_Reading_Krashen_.pdf.

[19] Lee, Bock-Mi (1996). Lectures on Language Learning \& Acquisition: What Do We Know When We Know a Language. Kuala Lumpur: Pustaka Antara SND. BHD.

[20] Lessow-Hurley, J. (1990). The Foundations of Dual Language Instruction. New York: Longman.

[21] Levy, S., Osborn, M., \& Plunkett, M. (2003). An investigation of international students' academic and social transition requirements' Enhancing the transition to higher education: strategies and policies that work, proceedings of the Seventh Pacific Rim Conference [on] First Year in Higher Education, 9-11 July 2003, QUT, Brisbane, Australia, edited by D Nulty and N Meyers. Brisbane: Queensland University of Technology 2003.

[22] Macaro, E. (2001). Learning Strategies in Foreign and Second Language Classrooms. London; New York: Continuum.

[23] Makepeace, E. E. (1989). Overseas Students: Challenges of Institutional Adjustment. SCED Paper (56) Birmingham: Birmingham Polytechnic.

[24] O’Malley, J. M. \& Chamot, A. U. (1990). Learning Strategies in Second Language Acquisition. Cambridge, England: Cambridge University Press.

[25] Oxford, R. L. (2003). Language learning styles and strategies: An overview. Learning Styles \& Strategies, 1-25. Retrieved October $10^{\text {th }}$, 2006 from http://hyxy.nankai.edu.cn/jingpinke/buchongyuedu/learning\%20strategies\%20by\%20Oxford.pdf.

[26] Prodromou, L. (2006). From Mother Tongue to Other Tongue. British Council. Retrieved October $10^{\text {th }}$, 2006 from http://www.teachingenglish.org.uk/articles/mother-tongue-other-tongue.

[27] Richard-Amato, P. A. (1996). Making it Happen: Interaction in the Second Language Classroom: From Theory to Practice. White Plains, NY: Longman.

[28] Richards, J. C. \& Rodgers, T. S. (1986). Approaches and Methods in Language Teaching: A Description and Analysis. Cambridge: Cambridge University Press. 
[29] Ringbom, H. (1986). Crosslinguistic influence and the foreign language learning process. In E. Kellerman \& M. S. Smith (Eds.), Crosslinguistic Influence in Second Language Acquisition (pp. 150-162). New York: Pergamon Institute of English.

[30] Robertson, M., Line, M., Jones, S., \& Thomas, S. (2000). International students' learning environments and perceptions: A case study using the Delphi Technique. Higher Education Research and Development, 19(1), 89-102.

[31] Spencer-Oatey, H., \& Xiong, Z. (2006). Chinese students' psychological and sociocultural adjustments to Britain: An empirical study. Language, Culture and Curriculum, 19(1), 37-53. Retrieved April 1, 2008, from http://www.tandfonline.com/doi/pdf/10.1080/07908310608668753\#.UohW8BbWHFI.

[32] Spolsky, B. (1999). Second language learning. In J. A. Fishman (Ed.), Handbook of Language \& Ethnic Identity (pp. 181-192). Oxford: Oxford University Press.

[33] Ventriglia, L. (1982). Conversations of Miguel and Maria: How Children Learn English as a Second Language: Implications for Classroom Teaching. Reading, Mass.: Addison-Wesley.

[34] Vygotsky, L. S. (1978). Mind in Society: The Development of Higher Psychological Processes. Cambridge: Harvard University Press.

[35] Wenden, A., \& Rubin, J. (1987). Learner Strategies in Language Learning. Englewood Cliffs, New Jersey: Prentice Hall.

[36] Wintergerst, A. C., DeCapua, A., \& Verna, M. A. (2003). Conceptualizing learning style modalities for ESL/EFL students. System, 31(1), 85-106

[37] Wu, Huifang (2002). Advantages and disadvantages of adults' English learning and the teaching methods. Educational Journal of Adult Higher Education, 4, 61-62.

[38] Wu, R. T. (2013). Non-English-Speaking International (NESI) Students' Tertiary Learning Strategies in Relation to English for Academic Purposes. Kuala Lumpur, Malaysia: Arab World English Journal. Retrieved November 24 , 2013, from http://www.awej.org/images/Theseanddissertation/RuiTingWu/119\%20full\%20thesis.pdf.

[39] Ying, Yu-Wen. (2003). Academic achievement and quality of overseas study among Taiwanese students in the United States. College Student Journal, 37(3). Retrieved April 1, 2008, from http://web.ebscohost.com/ehost/detail?sid=a32ba484-6df0-4929$9 \mathrm{a} 01-$ e14d07bdec96\%40sessionmgr110\&vid=1\&hid=108\&bdata=JnNpdGU9ZWhvc3QtbGl2ZQ\%3d\%3d\#db=f5h\&AN=10794954

[40] Ying, Y., \& Liese, L. H. (1991). Emotional well-being of Taiwan foreign students in the US: An examination of pre- to postarrival differential. International Journal of Intercultural Relations, 15, 345-366.

[41] Yule, G. (1996). The Study of Language. Cambridge, UK: Cambridge University Press.

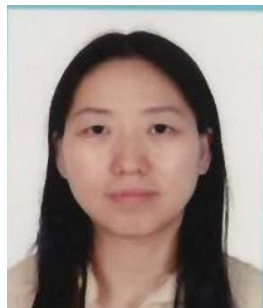

Rui Ting Wu A PhD candidate at the Faculty of Education, University of Tasmania, Australia. She is also an experienced School educator, having taught thousands of students from Prep to Year 12. Ms Wu holds a Bachelor of Teaching with Honours and a Master of Education in TESOL from the University of Tasmania, Australia. Her research interest is TESOL, primary teaching, and teaching Chinese as a second language.

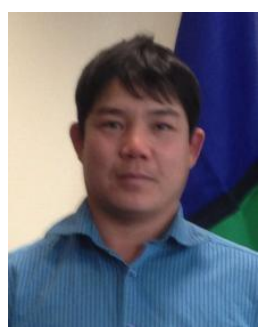

Van Tai Le An MBA student at The Tasmanian School of Business and Economics, University of Tasmania. Mr Le has completed a Bachelor degree in Aquaculture and a certificate IV of Supervision in Hospitality. His research interest is in the areas of Aquaculture, Economics, and TESOL.

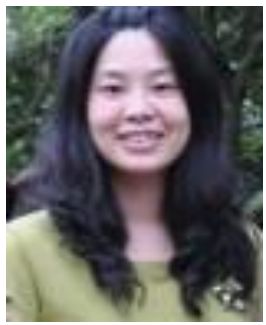

Jin Jin Lu A PhD student at the Faculty of Education, University of Tasmania. Her research interest is TESOL and Higher education. She has been working in a Chinese university as a lecturer for more than 7 years. 